\title{
Decolonial reflections on urban pedagogy in India
}

Dr. Jayaraj Sundaresan

Department of Geography and Environment,

London School of Economics and Political Science

This is a Draft. The Final Paper citation:

Sundaresan J. Decolonial reflections on urban pedagogy in India. Area. 2019;

00:1-9. https://doi.org/10.1111/area.12596

Abstract

This paper engages with deep and entrenched coloniality of the urban pedagogy, epistemology, and policy in India. After outlining the context, I will discuss my reflections on some relevant pedagogical initiatives that I had an opportunity to be part of as a faculty in a graduate-level programme in India.

"We need to rattle our bags to begin with and not just caddy for those who play" (Menon 2015)

\section{Introduction $^{1}$}

Critiquing the dominance of western experience and intellectual traditions in urban theory, Robinson (2002) calls for decolonisation of urban studies by 'restructuring the terrain' so that theory generated in and from specific places/experiences can travel and illuminate other places/experiences. What conditions shape this 'terrain' in the postcolonial contexts and what needs restructuring to enable a genuine 'dialogic' non-hierarchical cross cultural epistemological exchange, (Chakravarthy 2005)?

In this essay I take inspiration from calls across the world to decolonise knowledge and pedagogic practices to discuss the coloniality of contemporary mainstream urban (design, planning, policy) practice and pedagogy in India, particularly the importance given to northern/western frameworks. ${ }^{2}$

\footnotetext{
${ }^{1}$ I wish to thank two anonymous reviewers and Amlan Goswamy, Shriya Anand and Kavita Wankhade from IIHS for helpful comments.

${ }^{2}$ West and North are used interchangeably corresponding to the period discussed.
} 
Here, coloniality is understood as a state of mind and practice involved in the hegemonic (re)production of governable subjects through adoption or continuation of protocols (epistemologies, ideologies, representations, techniques, tactics, instruments, relations) of the colonial period. Decolonial practices aim to reveal and dismantle this power relation in knowledge, institutional practices and the self to enable alternate ways of understanding and being.

Intellectually, mainstream Indian urban pedagogy and practice is best characterized as 'schizophrenic'; while it seeks ultimate validation from the master, it also seeks to define itself in exception. Its sense of self-worth and confidence rests on the approval from (or reference to) master's house. It reproduces what Altalas (1974) called a 'captive mind'; paralysed by the western thought it is unaware of its own captivity. After a discussion on the context, I will discuss some creative/disruptive pedagogical initiatives that I partook in a graduate level program in India.

\section{Urban Policy/practice}

A senior planner in Bangalore once told me: "honestly, we [planners] really don't know what to do" about most of the problems in Bangalore; so s/he has "become big fan of people's solutions". ${ }^{3}$ This sense of epistemic disempowerment and the planner's discovery of people's solutions is concomitant with its opposite in Indian planning - the epistemic certitude of many planners/bureaucrats that India's superpower future is through making 'world-class' cities and that many people are an impediment to that project. Examining the coloniality of Urban Planning/Design domain in India helps to understand this better.

Firstly, India's current urban structure dominated by primate cities, comes from the colonial rule that established port/trading centres, capitals, hill stations, plantations, cantonments and residency towns (King 2007). Secondly, 'urban' as a category itself is connected to the process of governmentalizing the colony through instituting local municipal governments starting from Madras

\footnotetext{
${ }^{3}$ Interview (2008-2010)
} 
in 1687 (Simon 1930). Thirdly, 'urban' as adopted in independent India's census method during 1960s and 1970s not only accepted the colonial categorization of settlements until then, but also introduced new criteria on density, male employment and governance drawn from the Chicago School and International Urban Research Unit of University of California (Col 1961; p:7,11,12,16). Fourthly, most policy officials and policy elites seem to trust that international experts in the global north have solutions to problems in urban India, some of which are entirely new to planning theorylike adequate housing or waste management for a 20 million city, or regulating land and building use in cities that do not follow regulations.

A two day international conference (titled 'Re-inventing Delhi') organized by National Institute of Urban Affairs (NIUA) in February 2019 to support Delhi Master planning process convened 20 "eminent urban thinkers, practitioners and city administrators" to "re-evaluate the present planning paradigms and potentially reinvent" Delhi's future (NIUA 2019). Most of the 8 Indians among them moderated Q\&A, and International experts (from UK, US, Europe) gave the gyan. ${ }^{4}$ Learning from diverse experience is welcome of course, although urban experts from India doesn't get invited to provide insights for planning London, New York or Paris.

Let us consider this pattern in context.

Since independence (1947), Anglo-Euro-American consultants designed innumerous planning, infrastructure and development programs (city masterplans, industrial clusters, special economic zones, infrastructure projects, slum redevelopment schemes) that fundamentally (re)shaped India's habitats. A French consortium prepared recent Bangalore and Mumbai Masterplans even though

\footnotetext{
${ }^{4}$ insight/knowledge
} 
largest city in France is only $1 / 4^{\text {th }}$ of Bangalore and $1 / 8^{\text {th }}$ of Mumbai (population). ${ }^{5}$ A British consultant is currently designing Amaravati - the new capital city for Andra Pradesh. ${ }^{6}$ US consultants have designed many private cities in the past few decades replicating new urbanist enclaves. ${ }^{7}$ National urban (and rural) missions are theme and variation from the solution template of International development agencies/consultants. This trend, initiated during the Independence decade (1950/60's) saw Ford Foundation sponsored US architects prepare post independent India's first city masterplans (Delhi and Kolkata) and Swiss architect Corbusier design the first capital city (Chandigarh). During its inauguration Prime Minister Jawaharlal Nehru said it is a knock on India's head to make it think, to wake up from the slumber of static tradition towards progressive and liberating modernity. The knock was so hard that we perhaps didn't wake up at all; long list of such liberating development programs since Independence is one of the largest heavy-duty imports paid for by the people, sometimes with their life and livelihoods.

The Institute of Town Planners India (ITPI), was set up in 1947 emulating Royal Town Planning Institute (RTPI). Indian National Trust for Art and Cultural Heritage (INTACH), set up thirty five years after independence to conserve the national cultural heritage emulated the National Trust of England. ${ }^{8}$ Menon (2017) argues that INTACH "succeeded in training a substantial cadre of young professionals in the best traditions of English conservation practice" (p.88). Indian Institute of Geographers Journal is named 'Transactions' after the Royal Geographic Society's Journal. ${ }^{9}$ Good city, urban practice and education frameworks are thought as something to be borrowed from developed north and its 'world class' cities and institutes. Government officials visit New York,

\footnotetext{
${ }^{5}$ Bangalore masterplan consortium included Paris Municipality's planning department. See https://www.apur.org/en/about-us (last accessed-15/04/2018), Sundaresan (2019). On Mumbai see http://www.egis-india.com/egis-in-action/projects/preparation-development-plan-greater-mumbai-2014-2034 (last accessed - 15/04/2018)

6 https://www.fosterandpartners.com/projects/amaravati-masterplan/(last accessed 15/04/2018)

7 See Lavasa in Pune - http://www.lavasa.com(last accessed 15/04/2018)

${ }^{8}$ To move beyond colonial era 'Archaeological Survey of India' (set up in 1861)

${ }^{9}$ See http://www.itpi.org.in/ http://iigeo.org/
} 
London, Singapore etc., to study best practices to tame 'wicked' Indian city and disobedient 'Indian people' and square the 'immature democracy'. Yet most of the urban remains non-compliant with the Plan (violations), planning epistemology, modern bureaucratic economy and ideal typical representational democracy (Sundaresan 2019). Mainstream pedagogy and policy's enthusiasm for emulating northern practices is blind to the theoretical and progressive possibilities of multiple vernacular urbanisms in India. The expert seems to be clear about their reference list, but not on the problem set.

Post independent India didn't ask appropriate and relevant questions about the political geography of its habitats to devise imaginative and democratic planning methods. Consequently, planning system is a patchwork of colonial practice and outdated bits from UK and US. All formal planning methods currently used-from building, density and land use controls to the planning system itself were invented in some western country at some other century for some other reason. Current urban planning is best portrayed as continuation of building 'civil lines' and controlling the native (zoning, green belts, urban designed order); if not then it is sold by international development agencies/banks or consultants as best practice. ${ }^{10}$ Indian cities are not only 'planned in English', but masterplans are also only published in English and seldom ever consulted with people. ${ }^{11}$ Bastis that constitute half of most cities are bounded of as 'unclassified' and made invisible in many masterplans. Current national urban policy draft though mention that Indian Urban Planning has been 'western', it mostly draws from McKinsey Global Institute, World Bank and UN-Habitat; it proposes North American neo-traditionalist 'code based' zoning (MoH 2018).

Considered incapable of original thinking and imagination, the local (governments, people, institutions) is seen as geography to be controlled, reformed and educated, through 'capacity

\footnotetext{
${ }^{10}$ For example, see Cities Alliance (2012)

${ }^{11}$ The irony is London Plan is available in Gujarati, Tamil, Punjabi etc., upon request
} 
building' programs designed by people at the top. ${ }^{12}$ This 'capable and worldly' top that knows and the 'incapable local' at the bottom that just implements and enforces master's wisdom is the fundamental ingredient of the colonial relation. As Krishna Kumar (2005) argued, "in the colonial view, knowledge and the capacity to inquire were the colonizers unique privileges; the native was supposed to be ignorant and passive" (p.48). To view themselves, the natives seek and the masters' provide their 'lens', mainly inculcated through the urban and policy education in India.

\section{Epistemology, University and urban education}

Many influential anti-colonial social and educational reformers in India during the independence movement admired the knowledge (and institutions) that created the western industrial mammoth (Kumar 2005, Chakrabarty 2005). Undoubtedly, that influenced adoption of modernization as the development paradigm during early decades of independence. However the unremitting continuity of this servile attitude over past seven decades is puzzling, despite the glaring local and global disasters and inequalities created by the industrial mammoth and its knowledge across the world. I suggest, much of this can be attributed to how post-independent India's mainstream urban pedagogy developed from its colonial origins borrowing the "lens".

Courses related to Urban are offered in professional/technical and liberal arts colleges. Urban Planning is accredited by the RTPI styled ITPI that helped to establish the first Planning School in Delhi (1955). Similar bureaucratic accreditation control Architecture, Urban Design and Landscape courses, also serving as a gateway to jobs. In liberal arts colleges, colonial disciplines like sociology, anthropology, geography or development studies engage with urban questions, and is deeply

\footnotetext{
${ }^{12}$ See national capacity building program http://amrut.gov.in/content/innerpage/capacity-building.php(last accessed 25/09/2019)
} 
influenced by Anglo-Euro-American debates. Geographer Kapur (2004) notes that post independent India's social science education was influenced indirectly by the US, through UNESCO's 1954 Delhi conference on 'Teaching social sciences in South Asia' chaired by an LSE professor, and the modernist national planning programs. Patel (2011) notes how Indian sociology evolved through challenging or accepting the sociological traditions structured by colonialism and ideologies of nationalism; debates on indigenous sociology of India that Patel (2010) discusses hardly figure in the urban planning/design pedagogy. Further, returning scholars trained in the metropole has been a major influence across disciplines.

Singh (2013) argues that importing Anglo-American concepts and models have made Indian geography 'ill'. Indian authors represented only $20 \%$ of recommended readings in the 1989 national model geography curriculum (Kapur 2004). In the 2018 draft published by the University Grants Commission (UGC), it is $20 \%$ for Urban Geography; $10 \%$ for Political geography and $0 \%$ for Regional Planning and Development (UGC 2018). In Urban Planning model curriculum (2012), Indian authors or India focused resource material is absent for Planning History and Theory, Planning Techniques, Urban Heritage Conservation, Urban Planning Studio-1, Land Markets and Management, Environment and Development/Design, Politics and Public Policy (AICTE 2012). B-Arch Model curriculum stipulates only books by US academics for Sociology, Physical Planning, and Principles of Design (AITC 2013). Consequently, Anglo-Euro-American degrees, journals and publishers have higher value in Indian job market. Teaching methods and instruments, conceptual categories and epistemic frameworks are articulated almost only in English and borrowed from global north universities- some of which are now challenged as colonial and white even in the global north. ${ }^{13}$ The 2017 NIUA report (Asian Development Bank supported) on urban planning education in India is silent about this dominant epistemic infrastructure; instead they benchmark planning schools in UK,

\footnotetext{
${ }^{13}$ See 'why is my curriculum white' campaign at UCL http://www.dtmh.ucl.ac.uk/videos/curriculum-white//last accessed 15/04/2018).
} 
US, Singapore and Australia (NIUA 2017). It recommends inviting international experts to get exposure "of the global and state of the art thinking in the planning world" ( $\mathrm{p} 23$, emphasis mine). Only 2 of the 45 references cited in this report are about Indian Planning! This 'catching up' with knowledges (implicitly western) also appears in Kumar (2016), even as he proposes to learn from slum community activism for planning pedagogy in India.

The Higher Education (HE) governance system in India is derogatory, bureaucratic and exclusivist; it seldom consider academics and students as capable of quality original research/thinking. UGC mandates that every PhD student should publish a peer reviewed journal article before they can be awarded the degree; it doesn't believe that institutes and supervisors can ensure quality (see Prasad 2019). In the three-tier system of HE, research freedom/support reduces substantially as one move downwards from central government funded autonomous elite universities (Indian Institute of Technology-IIT, Indian Institute of Management etc.) to regional state and private universities. Technical Education Council rules require an Assistant Professor to have 'not less than' 16 contact hours per week which leaves little research time (AICTE 2019, p.29). ${ }^{14}$ This elite structure further sustained through exclusive access reproduces existing socio-economic privileges. ${ }^{15}$ The insane competition to enter public and private funded professional colleges (1:60 for IIT) causes deep anxiety to students and their families -millions spend significant resources from secondary school onwards preparing for various entrance examinations in specialised coaching centers/towns (see Lakshmi 2016). Those who don't get lucky to clear these exams eventually pay millions for private college admission. For example, ongoing admission charges + fees for a middle level medical college could cost $£ 150,000$ and upwards; those doctors will seldom choose to work on urban public health.

\footnotetext{
${ }^{14}$ Associate and full Professor $=14$

${ }^{15}$ See, (Subramanian 2015) on IITs.
} 
Indian urban pedagogy is not only embedded within a system that uncritically emulate damaging practices from western universities including rankings, but also within patriarchy and feudalism; caste, class, gender and language based exclusions; ${ }^{16}$ political capture of university and colonial hierarchical relations. Only the 'obedient Indian' fits in this scheme, not the 'argumentative' one: the faculty is simultaneously controlled and control students. Challenging (let alone co-construct) irrelevant and damaging curriculum, pedagogy and experience usually prove very costly for students (See, Ilaiah 2016).

\section{From my experience}

As an Architecture student in the 1990s at a reputable professional institution in politically conscious state of Kerala, we were actively discouraged to ask fundamental questions about the politics of knowledge imparted to us, let alone participate in politics. ${ }^{17}$ Instruction was exclusively in English even though it discomfited many faculty and students. The reference list, great buildings, great masters and great scholars were mostly Anglo-Euro-American and a few Indians who returned from western ateliers or universities. In history and design theory we mainly learned about Anglo-EuroAmerica or Indian Architecture framed by that epistemology. We brought expensive tracing papers and foreign made pens; one pen set costed three times my family's monthly income. Pruit-Igoe housing and collapse of modernist Architecture was taught (to teach western postmodernism) without its context - public housing, modern welfare state and institutionalized social/racial discriminations in the West. ${ }^{18}$ We learned Sociology from Anglo-American sociologists Maciver and Page's 1950 book rather than from debates in Indian Sociology. Even as the western debate in architecture between believers of industrial modernism and its critique from the Birmingham School was being enacted in Kerala then (Ommen 2018), our curriculum just uncritically followed the

\footnotetext{
${ }^{16}$ See (Jangid 2019) for a discussion on Hindi medium and HE; (Nair 2017) for Management bullying

${ }^{17}$ Yet we participated in vibrant campus politics surreptitiously.

${ }^{18}$ Built in 1950s and demolished in 1970s in US was taught widely as limitations of modernism: See (Fiederer 2017)
} 
former without exposing us to the latter, which was led by Laurie Baker. Baker's work was considered 'low cost building' than Architecture: he was seldom invited although practiced in the same city. ${ }^{19}$ The main curriculum taught neither about our own context nor of whatever was taught. When we documented traditional buildings and 'old settlements', it was to describe and archive, conserve, or borrow to post-modernize design. Many century old architectonics and socio-ecological relations/philosophies of habitation was seldom theorized, for which conceptual categories and language did not exist. Critical thinking was totally absent; for example- the relationship between reinforced concrete, tropical climate, sand mining, and related socio-ecological disasters. The pedagogic program focused on teaching images than imagination. We were asked to trace western trees/plants and human profiles in our rendering assignments. Aligning with 'examination' as the defining feature of Indian education system, we wrote 2 days long 'design exam'. Disenchanted with the curricula, some of us learned through our own enquiry, peer networks and travels.

In the late 1990's, for my postgraduate studies on Urban Design /Planning I attended an alternate university where contextual learning was emphasised: we studied diverse urban morphologies and lived realities across the country. However, Anglo-Euro-American masters, theorists and theories dominated our reading lists, conceptual categories, analytical frameworks and pedagogic interactions; it was either theme and variations or oriental exceptionalism. Either way ultimate reference point remained in Europe's cities, epistemologies and philosophies. Las Vegas, London, New York, Venice, Rome, Vienna, Paris, Berlin, Philadelphia dominated our reference list. Pedagogy of urban in India remained largely unaffected by some original pedagogical inspirations from Tagore, Gandhi, Paolo Freire, and Krishnamurthy in arts, humanities and primary education. It is in that

\footnotetext{
${ }^{19}$ Laurie Baker, an English man from Birmingham, inspired by Gandhi settled in and practiced from Kerala. See http://www.lauriebaker.net.
} 
context that Dilip Menon's quote at the beginning of this article becomes pertinent. Dilip Menon (2015) notes,

"In our universities we think with and teach a theoretical tradition forged in Europe in the last 400 years, rather than affirming that questions of self, community, politics and ethics have been the marrow of traditions of intellection in our spaces for a few thousand years".

Ascribing this pedagogic culture to colonial education reform of 1830 s entirely disguises Indian elites' enthusiasm to 'reform the native', drawing from European paradigms. ${ }^{20}$ Thus, 'what you know' becomes more important than 'what you think'. The 'successful' reviewed, referenced, emulated or regurgitated master's thoughts and practices well. The continuing coloniality in matters of government that frames the postcolonial as a subject rather than the citizen of rule for democratic sociality reinforces this. A public administrator once told me, "we are a developing country and so an immature democracy", i.e., only when we are developed can we expect democratic citizenship. This subjectivity becomes the fertile site where ideologies of colonial modernity becomes liberating rationality in which 'the local' when ontologically substituted as 'nodes of world economic system' is seen as empowering. Those who pioneered the colonial capitalist enterprise are seen as best placed to advice about the means and its critique.

Ordinariness and provinciality, like the master, is also postcolonial's worst fear.

\section{Is there a way forward?}

Decolonial questions in India are complicated; for who feels colonized by what varies. Questions are multidirectional: can western liberal modernity help those enslaved in local social structures (caste,

\footnotetext{
${ }^{20}$ Much quoted lines from Maculay's minutes of 1835 - "We must at present do our best to form a class who may be interpreters between us and the millions whom we govern; a class of persons, Indian in blood and colour, but English in taste, in opinions, in morals, and in intellect". (Sharp 1920-pp.116)
} 
class, religion, gender, sexuality); can vernacular ontologies and epistemologies liberate from the subjections of colonial modernity? Further, drawing from specific colonial constructions of Indian history and a specific European notion of nationalist state, certain versions of Hindu nationalism influence these questions in a perverse way that is deeply detrimental to the very constitution of society. However, in order to engage originally with these challenges too, it is important for a progressive higher education reform to address the epistemic and pedagogic underpinning that I discussed above.

Reform initiatives should aim for a diverse, democratic, grounded, critical and imaginative learning community by reworking the HE system assemblage- governance, accreditation, departments and disciplines, university boundaries, faculty, rankings, courses, research directions, epistemology, admissions, curriculum, reading list, delivery, assessment, assignments, fees, classroom, timetable, and campus politics among others. It should eventually dismantle exclusionary practices that reproduce social privilege; challenge disciplinary (and geographic) hegemony of conceptual categories and theoretical formulations; demystify 'theory' and encourage new conceptual vocabularies and theorisation; position knowledge within its political economy, geography and identity; build imagination to think, to do and to be. It should help to shape a mind of independent enquiry through contextual pedagogic practice and relief from referencing the master for self-worth. As Krishna Kumar (2005) puts, it should bring 'home and the classroom' closer to each other, for transformative engagement is educational in itself. I don't believe that a single point of power exist from which such an undertaking can and should be implemented all at once. Further, the contentious nature of it means that social movements led reform process will be more effective, in which incremental and strategic initiatives in experimental avenues have an important role. Such initiatives should, as Mingolo (2013) puts it, aim to 'change the terms of the conversation, not just its content'. 


\section{Reflections on one initiative}

Below, I shall briefly discuss some relevant initiatives that I partook at Indian Institute for Human Settlements (IIHS) while teaching at the first graduate level, 9 months, fully funded Urban Fellows Program (UFP-2016/17). ${ }^{21}$ These initiatives though barely scratched the surface of many issues discussed above, I believe it provide some entry. Pedagogic initiatives are developed, implemented and delivered collectively in IIHS, of which I was a member from 2010 till 2017. Therefore all initiatives discussed here are devised collectively. ${ }^{22}$ IIHS came together as the result of a few people asking questions about urban policy, epistemology and pedagogy in India (and global south) given that,

1) Massive urbanization of the subcontinent (and global south) in the 21st century significantly influences global urbanization,

2) Epistemic, pedagogic and policy practices follow canonical urban theory generated by and from the experience of global north and not fit for purpose.

IIHs collective originally did not deploy decoloniality as conceptual framework to develop initiatives discussed here; so these are my own reflections on some initiatives. Having studied and worked in India and London as an academic and professional practitioner across urban, planning/design and development domains, and researching on urban planning/design in India and London, my own learning/unlearning process is shaped by critically reflecting on the relationship between epistemic practices, context and connections. Decolonial approaches helped me to unravel the coloniality of these connections- including how knowledge about south from the north is productive of unequal power relations and embedded in the northern academic industrial complex- well-funded participant observer, theorizing from far, unequal research opportunities, occasional field work,

\footnotetext{
${ }^{21}$ http://urbanfellows.iihs.co.in/

${ }^{22}$ With Shriya Anand I co-directed 2016-17 UFP; it was developed and implemented by entire IIHS staff across academic, research, practice and operations team; too many names to mention individually here.
} 
'development' practice or its critiques, neo-colonial collaborative grants/partnerships and research assistance, competition driven performance, disciplinary silos, publication politics, media marketing, dominance of English language, Anglo-Euro-American conceptual categories and preoccupation with western philosophical debates among others.

Interdisciplinary and inter-practice enquiry: Academic disciplines' discipline epistemic enquiry; it shapes scholarship and pedagogy through its vocabulary, methods and production economy. Challenging discipline's claim to epistemic authority through interdisciplinary enquiry, I believe is central to decolonizing knowledge and pedagogy. Inter-disciplinarity involves deploying multiple disciplinary approaches to examine each other's vocabulary and epistemic claims to arrive at fundamental questions.

UFP invited application from all disciplinary backgrounds, resulting in a class room of engineers, artists, architects, lawyers, social scientists and writers. Teaching formats conceptualized 'urban practice' as an inter-disciplinary and inter-practice program and adopted 'Commons' (first term) and 'Electives' (second term) for structuring the year. ${ }^{23}$ 'Urban Practice' recognize epistemic and transformative values in multiple practices, rather than only privileging academia. Researchers, public administrators, consultants, artists, activists, journalists and editors either co-taught regular courses or delivered half-day sessions where specific experience was discussed under confidence. Each school in IIHS offered one team taught module in 'Commons' bridging different disciplinary backgrounds. ${ }^{24}$ Shared case-studies (example- entanglement of caste and sanitation; wetlands/drainage ecology of Bangalore) connected different modules with each other. ${ }^{25}$ Diverse spaces, modes and formats- lectures and seminars, week long immersion field visits, term long

\footnotetext{
${ }^{23}$ IIHS Curriculum framework in (Balakrishnan et.al 2013)

${ }^{24}$ Schools organized around interdisciplinary research programs- economic development, law and governance, human development, settlements and infrastructure, etc.

${ }^{25}$ See IIHS case development project http://cases.iihs.co.in/
} 
practica-studios, public lectures/events, presentations, conference/workshops, assured internship etc., helped to maximize strength (than deficit) based learning. Everyone studied 4 cities in person and interact with many people, institutions and practice domains across India.

University, classroom and its diverse outsides: Through exclusivist application/admission modes, notion of excellent candidate, hierarchical grading and so on, the modern university reproduce existing socio-economic privileges. Therefore, we asked how should we shortlist; who should be in the classroom; who is this 'excellent' applicant/candidate? The diversified (across gender, sexuality, ideology, experience) admissions committee developed a scheme to arrive at the final list through negotiations. Fixing minimum qualification at 'high school education' and 'ability to read English' helped to attract experienced activists who had little opportunity for formal education and vernacular language speakers from smaller cities. Multiple criteria used to shortlist applicants for interview recognized 'potential' of the candidate, examining how far they have come in life using opportunities they had rather than restricting to disembodied criteria of 'achievement'. ${ }^{26}$ The ability to ask grounded, original, reflexive questions from experience was given importance. Such initiatives enabled a classroom with linguistic, academic, professional and socio-economic diversity, including high proportion of first generation learners.

Diversity transformed usual timetable formats- for example, lectures and seminars got extended into longer discussions that enabled learners to comprehend specialist disciplinary vocabulary and ask fundamental questions. It enabled viewpoint diversity and peer learning. For example, in one assignment, learners were asked to bring back stories by talking to people in the city. Some stories enabled by viewpoint diversity shocked many because it revealed misogyny, caste-ism, communalism, regionalism etc., in Bangalore. Diversity pushed the faculty to devise appropriate

\footnotetext{
${ }^{26}$ In addition to positive discrimination criteria based on caste, it included nature of school, family's higher education status among others.
} 
conceptual vocabularies and delivery methods like bilingual lectures/seminars, separate Hindi briefing sessions, Hindi and English assignments and language skill labs.

Co-constructing resources: In Planning and Community elective I offered, we focused to study ongoing participatory planning activism in Bangalore. Students attended the meetings along with faculty, spoke to activists and was offered an opportunity to participate in the process. Instead of a prior reading list, references were collated every week as a result of the questions that the students generated from meetings. Thus the classroom became a space where knowing was shaped by enquiries that emerged from witness and experience rather than a space from where 'knowledge' made multiple experiences, questions and information irrelevant. Diversity shaped this process: for example, a lawyer enquired questions on planning-law and community participation, while a socialworker focused on planning activism, slums and caste.

Assessment: Assessment philosophy used assignments as an opportunity to learn skills (in analysis, articulation, writing, film making) to produce outputs and to archive their work. There were no exams; assignments were designed (sometimes students chose format- essay, film, presentation) to help students to produce 'their' best work rather than hierarchically order them for an outside (higher studies, job market).

Imagination: imaginative propositional thinking was central to pedagogy. This was organized through a design research studio where learners collectively researched on specific current issues in Bangalore, acquired skills and networks, co-constructed analysis, developed affective relationship with field, critically examined epistemic and policy representations and proposed imaginative propositions through engaging with faculty, peers, field and reference list. The close and reflexive relationship that learners developed with people, histories, institutions and field were part of learning outcomes. 
Learning community: Notion of 'learning community' shaped ethos of the program. All shared same lunch space, calling each other by first names rather than the colonial salutation ('sir') norm in India and celebrating together after each term helped to break the hierarchical instructional relationship. Through multiple feedback avenues the students could and did openly challenge some components of the program resulting in its redesign along the way.

\section{Conclusion}

Many specific conditions enabled some components in UFP-2016/2017 to be assembled different from usual urban pedagogy in India. It started at a particular juncture in IIHS' trajectory of going through statutory recognition process; therefore being outside of professional accreditation and bureaucratic public administration helped. The program was delivered from a small city campus building where IIHS community worked and this enabled close interaction with core faculty. When these situations change in the future, perhaps pressures will be different too, which is my point that epistemic and pedagogic intentions should shape institutional program rather than vice versa. To be fair, I must note that UFP is not the first program where alternate methods have been explored in Indian urban studies. Though far and few between, I am aware of initiatives that are implemented by faculty and students reclaiming their autonomy and in disobedience with institutional orders of coloniality, like how Menon (2017) describes the INTACH trained conservationists discovered contextuality through practice. The dire state of urban pedagogy in India calls for reflexively documenting such initiatives.

Among the impediments to developing alternate pedagogy in India includes the job market (and western education aspiration) that demands colonised degrees and minds. Inadequate welfare and social security systems in India could create a delusion that colonised degrees are better for social 
mobility and that decolonization is the privilege of the elite. ${ }^{27}$ This is nothing but a cavalier path dependency argument; the urban condition in India is too dire to entertain such vacuous rhetoric, for it is the least privileged who suffer most not only from the discourse of 'skill-deficits', but also from dehydration, floods, sewage, waste mountains, homelessness, displacements, and so on. Therefore, the importance of sectoral reforms to decolonize the field can't be more emphasized. Coloniality shapes colonized epistemology and pedagogy, planning, policy, governance, city and society. It also has significance beyond India; as Nandy (1983) argued, "liberation ultimately had to begin from the colonized and end with the colonizers" (p.63), as the colonisers too are caught in sustaining their domination. How 'Rhodes Must Fall' spread from Cape Town to the Metropole I believe, is a testimony to that possibility.

\section{References}

AICTE (2012): Model curriculum for M.PLAN/M.TECH (Planning), AICTE, New Delhi AITCE (2013): Model curriculum for B.Arch, AICTE, New Delhi

AICTE (2019): Regulations on pay scales, service condition and minimum qualifications, AICTE Notification-F.No.61-1/RIFD/7th CPC/2016-17, New Delhi.

Altalas (1974): The captive mind and creative development, International Social Science Journal 24(4), pp.691-702

Balakrishnan et.al (2013): Masters of Urban Practice: Curriculum Framework Version.5.0, IIHS, Bangalore

Cities Alliance (2012): Cities without slums, Annual Report 2012, No.76132, Washington

\footnotetext{
${ }^{27}$ I am grateful to Ram Bhatt in LSE for this point
} 
Col (1961): An Approach to Urban Studies in India, Census of India report

Chakrabarthy (2005): Legacies of Bandung: Decolonisation and the Politics of Culture, Economic and Political Weekly,40(46),pp.4812-4818

Fiederer (2017): Pruitt-Igoe Housing Project/ Minoru Yamasaki, Archdaily, 15-May-2017

Ilaiah (2016): Rohit Vermula, death of a philosopher to purify higher education, Hindustan times, 20January-2016

Jangid (2019): There is much more to JNU than left politics for a Hindi medium student, The Wire, 13-May-2019

Kapur (2004): Geography in India: A Languishing Social Science, Economic and Political Weekly, 39(37), pp.4187-4195

King 2007: Colonial urban development, Routledge, Oxon

Kumar (2005): Political agenda of Education. A study of colonialist and nationalist ideas, Sage, New Delhi

Kumar (2016): An exploration into multiplicity of planning knowledges, in Kumar et.al (eds), Urban and Regional Planning Education: learning for India, Springer, Singapore

Lakshmi (2016): A spate of suicides highlight pressures of students in India, Washington Post, 26-Jan2016

Menon (2017); The Idea of Place in the Practice of Restoration and Replication in India, in Weiler K., Gutschow N.(eds); Authenticity in Architectural Heritage Conservation. Transcultural Research, Springer, Cham

Menon (2015): Lessons from India on decolonizing language and thought at universities, The conversation, Aug 31, https://theconversation.com/lessons-from-india-on-decolonising-languageand-thought-at-universities-46541 (last accessed 15/04/2018)

Mingolo (2013): Geopolitics of sensing and knowing: On (de)coloniality, border thinking and epistemic disobedience, Confero, 1(1):129-150 
MoH (2018): National Urban Policy Framework (draft), Government of India, New Delhi

Nair (2017): Kerala's Jishnu Pranoy suicide and its political ramifications, Hidustantimes 15-April2017

Nandy (1983): The intimate enemy: Loss and Recovery of Self under Colonialism, OUP

NIUA (2019): Reinventing Delhi, International conference Brochure, New Delhi, available from https://smartnet.niua.org/sites/default/files/re-inventing delhi brochure final.pdf (last accessed 28/06/2019)

NIUA (2017): Recommendations for an Improved Master's Level Urban Planning Curriculum, Delhi, India

Patel (2010): Sociology's other: Debates on European Universals, in Charles Crothers(ed), Historical developments and theoretical approaches in Sociology-Vol II, EOLSS/UNESCO

Patel (2011): Ruminating on Sociological traditions in India, in Patel(ed), Doing Sociology in India: Genealogies, Locations and Practices, OUP, Delhi

Prasad (2019): Paper publication prior to PhD thesis rule may go, The Hindu, June 11, 2019.

Sharp (1920): Selection from educational records-Part-I, 1781-1839, Bureau of Education, India

Simon (1930): Simon commission report on India Volume-1, reprint (1988), Swati Publishers, Delhi

Singh 2013: Geography in the eyes of geographers: Indian Context, in Sharma et.al (ed), Interdisciplinary advances in Geography, R.K.Books, Delhi

Subramanian (2015): Making Merit: The Indian Institutes of Technology and the Social Life of Caste, Comparative Studies in Society and History; 57(2):291-322.

Sundaresan 2019: Urban Planning in Vernacular Governance: Land Use Planning and Violations in Bangalore, Progress in Planning, 127, 1-23

Oommen (2018): Rethinking Indian modernity from the margins, Architectural Theory Review, 22(3):386-409

UGC (2018): Model Curriculum for Geography (draft), University Grants Commission, New Delhi 
